\title{
MORPHOLOGICAL VARIATIONS IN HUMAN LIVER: A CADAVERIC STUDY
}

\author{
Mansur DI, Shrestha P, Maskey S
}

Department of Anatomy, Kathmandu University School of Medical Sciences Dhulikhel, Nepal

\begin{abstract}
The variations of liver like the accessory fissures and lobes are a potential source of diagnostic errors. The knowledge in the variations may help in diagnosis, treatment planning and minimize the risk of post operative complications. The present study was aimed to observe the morphological variations of livers. The study was done in 70 formalin fixed human livers and was observed for morphological variations. The present study concluded the normal morphology of liver was in $54.28 \%$ and anomalies in $45.71 \%$ of liver. The most common anomalies were accessory fissures which were found in $32.86 \%$ of livers. The second common anomalies were absence or incomplete fissure for ligamentum teres in $15.71 \%$ of livers. Then the enlarged papillary process was found in $11.43 \%$, short gall bladder was in $10 \%$ and elongated left lobe was in $7.14 \%$. The knowledge of normal and variant liver may contribute to the understanding of the liver disease and to achieve correct preoperative diagnosis; and to avoid intra-operative complications.
\end{abstract}

\section{KEYWORDS}

Accessory fissure, additional lobe, anomalies, liver

\section{CORRESPONDING AUTHOR}

Dr. Dil Islam Mansur

Department of Anatomy,

Kathmandu University School of Medical Sciences, Dhulikhel, Nepal

Email: dilislam@kusms.edu.np

ORCID ID: 0000-0001-5958-0423

DOI: https://doi.org10.3126/nmcj.v21i4.27612 


\section{INTRODUCTION}

The liver is the largest gland in human body. It is divided into larger right lobe and smaller left lobe by the attachment of the falciform ligament. The right lobe is further divided into quadrate and caudate lobes by the presence of the gallbladder, the fissure for the ligamentum teres, the inferior vena cava, and the fissure for the ligamentum venosum. The small rounded elevation from left lower end of caudate lobe is known as papillary process. The fundus of the gallbladder usually projects beyond the inferior border of the liver. ${ }^{1}$ The liver develops from an endodermal evagination of the foregut and from septum transversum mesenchyme which is derived from the proliferating coelomic epithelium in the cardiac region. ${ }^{2}$

Abnormalities of liver are mainly concerned with variation in size, fissures and configuration of lobes. ${ }^{3}$ The variations have been observed in human liver and classified as congenital or acquired. ${ }^{4}$ A study also claimed that there are many kinds of described congenital abnormalities of the liver as agenesis of its lobes, absences of its segments, deformed lobes, decrease in size oflobes, lobar atrophy, hypoplastic lobes, transposition of the gall bladder and Riedel's lobe. ${ }^{5}$ Hepatic anomalies may be due to excessive growth during embryonic life or due to defective development of liver. The latter leads to formation of accessory lobes and fissures on the hepatic surface. ${ }^{3}$

The absence of normal fissures and lobes or the presence of additional lobes and fissures might lead to confusion on a radiological diagnosis of a liver disorder. ${ }^{6}$ Accessory lobe can be interpreted as tumors by novice radiologists. ${ }^{7}$ Fissures of the liver are used as demarcation sites for incision during hepatic surgeries. Accessory fissure can be interpreted as internal injury. ${ }^{8}$ Sulci can be present on the diaphragmatic surface of the liver which can also be the source of errors during radiological study. ${ }^{9}$

Though abnormalities of liver are usually asymptomatic, a possibility of the presence of these variations has to be kept in mind when an unexplained abdominal mass is encountered. ${ }^{5}$ Thus, this study was carried out to document the prevalence of morphological variations in fissures and lobes of liver among Nepalese population. The knowledge of these variations could be helpful for minimizing the possible complications during diagnostic and clinical procedures.

\section{MATERIALS AND METHODS}

This was the cross-sectional and retrospective study consisted of 70 formalin fixed human livers, irrespective of the sex. All the livers were collected from the Department of Anatomy, Kathmandu University School of Medical Sciences, Dhulikhel, Kathmandu Medical College, Duwakot and Nepal Medical College, Attarkhel, Kathmandu during the period of January 2017 - November 2017. Livers with normal configuration were included and livers with any damage or any pathology were excluded from the study. The ethical approval for the study was taken prior to the study.

The livers were recorded and analyzed for the morphological variations such as presence of accessory fissures and absence or incomplete fissure for ligamentum teres and venosum. The papillary process was considered enlarged if it was greater than $39 \mathrm{~mm} .{ }^{10}$ The gallbladder was considered short if it could not project beyond the inferior border of the liver. ${ }^{11}$ The left lobe was considered as elongated if it was more than 6.47 cm. ${ }^{11}$

\section{RESULTS}

A total number of 70 formalin fixed human livers of unknown sex were studied and made the following observations. Among 70 livers, $38(54.28 \%)$ livers were observed normal in their external appearance, number of lobes and fissures while 32 (45.71\%) livers showed one or more forms of morphological anomalies. Among the 32 livers that showed morphological anomalies 15 (21.43\%) livers showed two or more types of anomalies and 17 (24.29\%) had only one form of anomaly.

All together, five types of anomalies were recorded in the present study as shown in table 1. The most common anomalies were accessory fissures which were found in 23 (32.86\%) livers as illustrated in Fig. 1. The second common anomalies were absence or incomplete fissure for ligamentus teres which were noted in 11 (15.71\%) livers as shown in Fig. 2 and 3.

Similarly, the enlarged papillary process was found in 8 (11.43\%) livers as shown in Fig. 4, the short gall bladders were also noticed in $7(10 \%)$ livers (Fig. 5). Moreover, elongated left lobe were also seen in 5 (7.14\%) livers as illustrated in Fig. 6.

Table 1: Incidence of liver anomalies

\begin{tabular}{|llll|}
\hline sn & Anomalies & $\mathbf{n}$ & $\mathbf{\%}$ \\
1 & Accessory fissure & 23 & 32.86 \\
2 & $\begin{array}{l}\text { Absence of fissure for } \\
\text { ligamentus teres }\end{array}$ & 11 & 15.71 \\
3 & Prominent papillary process & 8 & 11.43 \\
4 & Short gall bladder & 7 & 10.00 \\
5 & Elongated left lobe & 5 & 7.14 \\
\hline
\end{tabular}




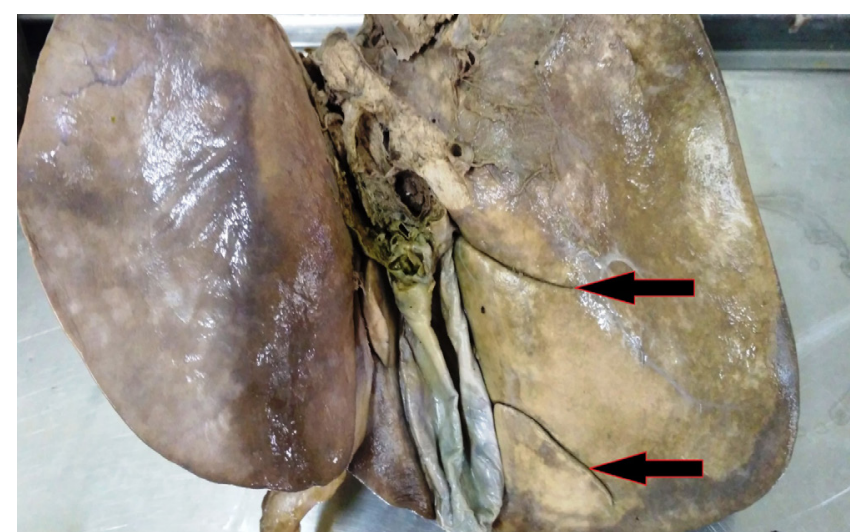

Fig. 1: Showing accessory fissures (Black Arrows mark)

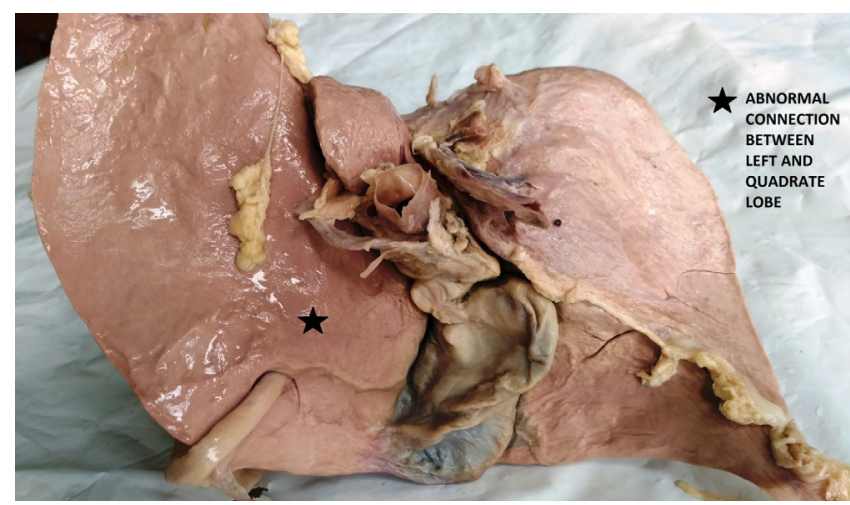

Fig. 2: Showing absence of fissure for ligamentus teres (Star mark)

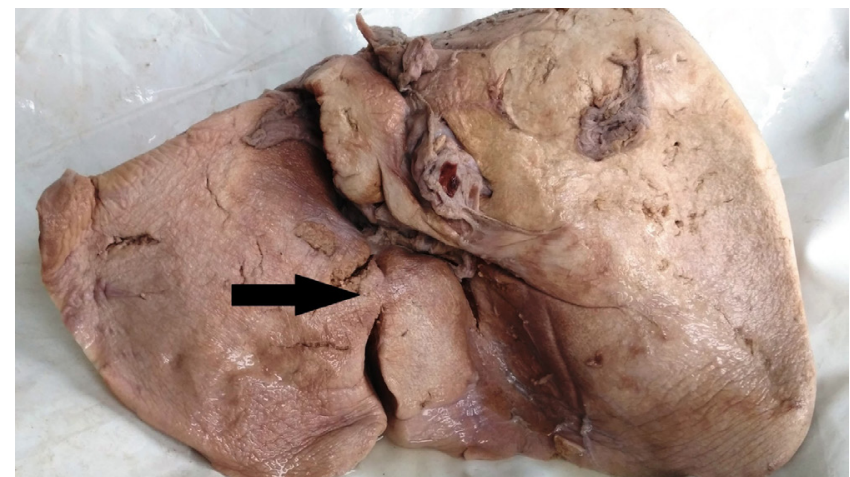

Fig. 3: Showing incomplete fissure for ligamentus teres (Black Arrows mark)

\section{DISCUSSION}

The human liver showed the variations in its external appearance, lobes and fissures which are considered as abnormality or anomalies. The knowledge of its abnormality becomes very important to clinician, surgeon and radiologist for minimizing the complications that it could build up during radiological diagnosis, hepatic interventions and other surgical procedures. The abnormality may be high in population which is not noticed; because they are usually asymptomatic. ${ }^{5}$ They may be diagnosed as accidental findings. The most of the morphological anomalies are either due to defective or excess development. ${ }^{13}$

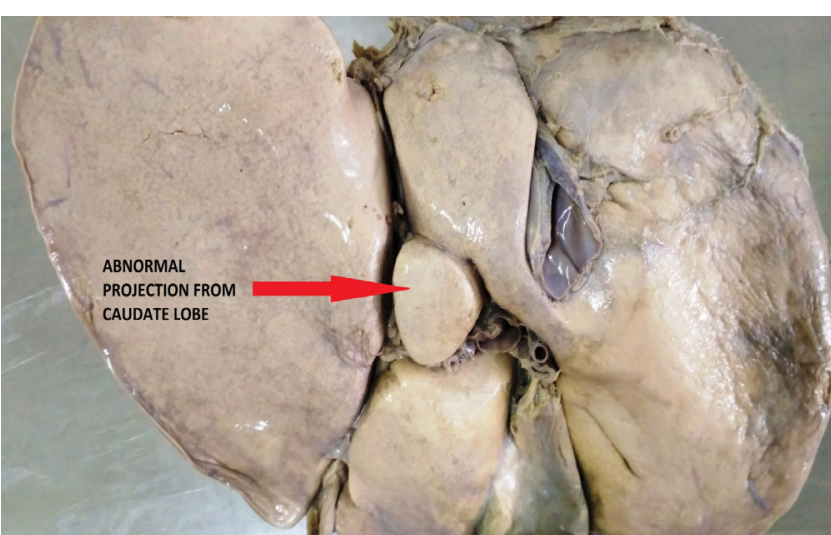

Fig. 4: Showing enlarged papillary process (Red arrow mark)

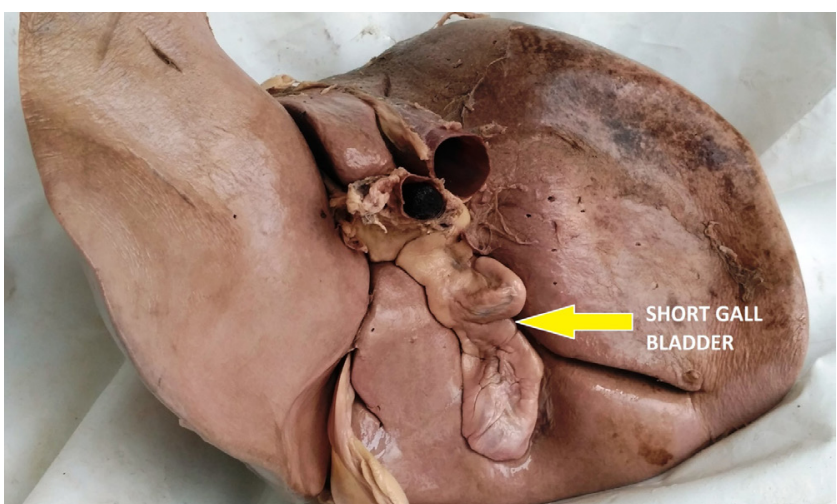

Fig. 5: Showing short gall bladder (Yellow arrow mark)

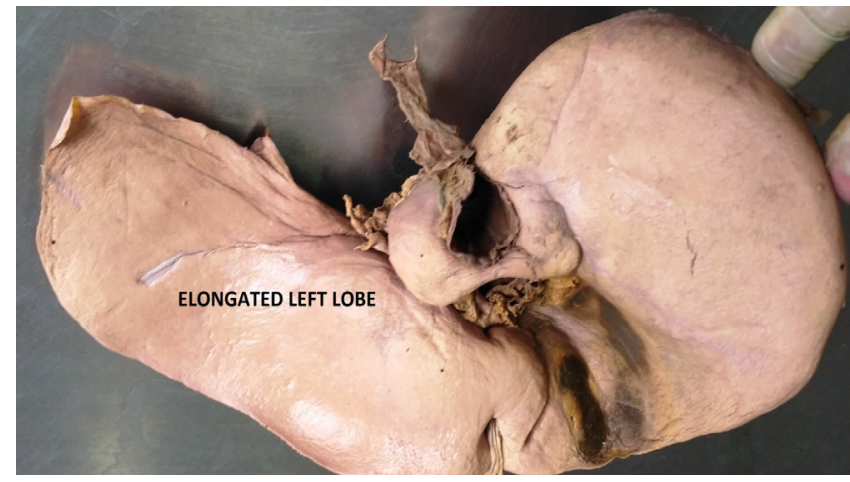

Fig. 6: Showing elongated left lobe

These anomalies were seen in $45.71 \%$ of the livers in the present study. Likewise, Wahane et al and Patil et al reported that $44 \%$ of the livers with anomalies in their study. ${ }^{14,15}$ Whereas Vinnakota et al reported $58.62 \%$ of livers had anomalies in their study ${ }^{16}$ and Nagato et al reported $57.4 \%$ of the livers in their study were not morphologically normal. ${ }^{17}$ These results shows higher frequency of occurrence of anomalies than our present study. Aristotle et $a l^{18}$ reported the presence of morphological anomalies in $41 \%$ of the liver in their study and Nayak ${ }^{11}$ reported it to be $40 \%$ in his study which is lower than the result obtained in the present study. 
Hepatic malformations are more common in the perinatal age group since most of the anomalies undergo reformation postnatally. ${ }^{19}$ Failure in the postnatal development of liver leads to the occurrence of anomalies in fissures. ${ }^{9}$ Variations in the fissures were recorded by many researchers. ${ }^{5,18} \mathrm{~A}$ study conducted by Vinnakota et al reported $53.44 \%$ of accessory fissures in their study. ${ }^{16}$ Similar another study was conducted by Patil et al and they revealed $14 \%$ of the livers had accessory fissures. ${ }^{15}$ In the present study, the accessory fissures were also present in $32.86 \%$ of livers. It is clear from this observation that variations in the fissures are common and these accessory fissures are the potential source of errors in diagnosis and imaging techniques. ${ }^{20}$ Collection of any fluid in accessory fissures may be mistaken for a cyst, liver abscess or intrahepatic hematoma. ${ }^{11}$ The multiple accessory fissures may mimic pathologic macro nodular liver on CT. The Fissure may be associated with diaphragmatic scalloping or eventration on chest film. ${ }^{4}$

Absence or incomplete fissure for ligamentum teres was found to be $15.71 \%$ of the livers in the present study. The similar finding was recorded by Aktan et al who noticed in $14.81 \% .^{5}$ Similarly, Patil et al reported that $10 \%$ of the livers had absence of fissure for ligamentum teres. ${ }^{15}$ On the other hand Nayak reported only $1.81 \%$ of livers with absence of fissure for ligamentum teres and it was due to fused quadrate and left lobe of liver. ${ }^{11}$

In the present study, it was found that enlarged papillary process was present in $11.43 \%$ of livers projecting from caudate lobe. Joshi et al did an extensive study on variations of the liver and found enlarged papillary process in $32 \% .{ }^{21}$ Sarala et al also revealed enlarged papillary process in $21 \%$ of the livers. ${ }^{22}$ In contrast, Nayak reported only one liver (1.81\%) had an enlarged papillary process. ${ }^{11}$ The variations in results among various authors may be due to ethnic groups, the type of study or the sample size.

The normal anatomy of the caudate lobe can create several pitfalls that may lead mistakenly to a diagnosis of disease. The probability of misinterpretation of CT images increases if the papillary process is involved in diseases or when papillary process is enlarged. Auh et al observed that on CT, a normal or small papillary process may be mistaken for enlarged porta hepatis lymph nodes. It is known that the enlarged papillary process can displace the gastric antrum and duodenum anteriorly, thus mimicking a right sided retroperitoneal mass. ${ }^{20}$

When enlarged papillary process extends on to left side it can mimic pancreatic body mass, such an enlargement is common in cirrhosis of liver. Caudate lobe enlargement commonly accompanies occlusion of the hepatic veins; along with patchy areas of low and high attenuation on CT. The explanation given is that the venous drainage of caudate lobe is by the emissary veins that pass directly from caudate lobe to inferior vena cava. ${ }^{23}$

The gall bladder is situated obliquely in the fossa for gall bladder on the on the under surface of right lobe of liver. It extends from the right end of porta hepatis to the inferior border of liver. Its fundus produces a cystic notch on the inferior border of the liver and projects beyond the inferior border to come in contact with the anterior abdominal wall at the angle of 30 degree just below the tip of the right ninth costal cartilage. ${ }^{24}$ Due to this contact with the anterior abdominal wall, infections of gall bladder may infect the parietal peritoneum and this in turn will lead to the pain at the tip of right ninth costal cartilage where the fundus of gall bladder makes contact with the anterior abdominal wall. ${ }^{11}$

In the present study, gall bladder was short in $10 \%$ of livers and botched to cross the inferior border of the liver. Similar study was conducted by Nayak ${ }^{11}$ and revealed gall bladder was short in $18.18 \%$ of cases and failed to cross the inferior border of the liver. In contrast, Mamatha et al reported the incidence of short gall bladder only in $2 \% .{ }^{6}$ The gall bladder may be short or atrophic when there are abnormal peritoneal folds like cystohepatocolic folds are present. ${ }^{25,26}$ Short gall bladders which hide in their fossa, may lead to confusions in imaging techniques and also in laparoscopic surgeries in the region. ${ }^{11}$

Several studies said that among liver malformation, left lobe may be long and thin, extended downward and to the left onto the left upper abdominal cavity even though right lobe take approximately $65 \%$ of liver volume in normal occasion. Elongation of left lobe may seem like spleen after splenectomy or large spleen for the surgeon, but it was definable because of free movement during respiration as it connected to liver. ${ }^{27}$ Changes of left lobe depend on many factors including, obesity, age of the patient, liver pliability, previous existence of splenomegaly and its duration that may mimic residual spleen after splenectomy, accessory spleen, mass lesion in the region of porta hepatis. ${ }^{28}$

In the present study $7.14 \%$ of the livers showed elongated left lobe which is comparable with a study which revealed in $7.10 \% .^{29}$ Where as the higher incidence of elongated left was also recorded by Arya et al in their study reported the presence of elongated left lobe in $15 \%$ of the livers. ${ }^{30}$ The lower incidence was also 
reported in $1.72 \%,{ }^{16} 3.30 \%{ }^{18}$ and $4 \%{ }^{14}$ of the livers. Defective development of the left hepatic lobe can lead to gastric volvulus. Conversely, defective development of the right lobe of liver either remains clinically latent or leads to portal hypertension. ${ }^{3}$

In conclusion, the incidence of morphological variations of liver is very high in this study. Thus accurate knowledge of such variations could be essential to Anatomists and Morphologists for new variant, Embryologists for new defect of development, Surgeons for planning appropriate surgical approaches and Radiologists for avoiding misinterpretation of radiological mages. A sound knowledge of the normal and variant liver is a prerequisite to have a favorable clinical practice.

\section{REFERENCES}

1. Snell RS. Clinical Anatomy by Regions. $9^{\text {th }}$ edition. Philadelphia: Wolters Kluwer Lippincott Williams and Wilkins; 2012: 196-7.

2. Standring S. Gray's Anatomy: The Anatomical Basis of Clinical Practice. $40^{\text {th }}$ edition. Churchill Livingstone: Elsevier; 2010: 1163-75.

3. Champetier J, Yver R, Letoublon C, Vigneau B. A general review of anomalies of hepatic morphology and their clinical implications. Anat Clin 1985; 7: 285-99.

4. Saritha S, Ramani, Nagajyothi, Yesender. Cadaveric study of morphological variations in the human liver and its clinical importance. Int'l J Med Sci Clin Invent 2015; 2: 1020-31.

5. Aktan ZA, Savas R, Pinar Y, Arslan O. Lobe and segment anomalies of the liver. I Anat Soc India 2001; 50: 15-6.

6. Mamatha Y, Chaitanya KM, Prakash BS. Study on morphological surface variations in human liver. Int'l J Health Sci Res 2014; 4: 97-102.

7. Tancredi A, Cuttitta A, Martino DG, Scaramuzzi R. Ectopic hepatic tissue misdiagnosed as tumor. Updates Surg 2010; 62: 121-3.

8. Bishmuth H. Surgical anatomy and anatomical surgery of the Liver. World J Surg 1982; 6: 3-9.

9. Macchi V, Porzionato A, Parenti A, Macchi C, Newell R, De Caro R. Main accessory sulcus of liver. Clin Anat 2005; 18: 39-45.

10. Donoso L, Martínez-Noguera A, Zidan A, Lora F. Papillary process of the caudate lobe of the liver: sonographic appearance. Radiology 1989; 173: 6313.

11. Nayak BS. A study on the anomalies of Liver in the South Indian cadavers. Int'l J Morphol 2013; 31: 658-61.

12. Joshi SS, Reddy N, Joshi SD, Mittal P. Morphological variations of left lobe of liver. Int'l J Contemporary Med Res 2017; 4: 1956-58.

13. Daver GB, Bakshi GD, Patil A, Ellur S, Jain M, Daver NG. Bifid liver in a patient with diaphragmatic hernia. Indian J Gastroenterol 2005; 24: 27-8.

14. Wahane A, Satpute C. Normal morphological variations of liver lobes: A study on adult human cadaveric liver in Vidarbha region. Int'l J Sci Res 2015; 4: 814-16.

15. Patil S, Sethi M, Kakar S. Morphological study of human Liver and its surgical importance. Int'l J Anat Res 2014; 2: 310-14.
16. Vinnakota S, Jayasree N. A new insight into the morphology of the human Liver: a cadaveric study. ISRN Anat 2013; 689564: 1-6.

17. Nagato AC, Silva MAS, Trajano ETL et al. Quantitative and morphological analyses of different types of human liver. J Morphol Sci 2011; 28: 275-9.

18. Aristotle S. Morphological study of anomalies of lobes and segments of human Liver. Int'l J Pharm Bio Sci 2016; 7: 810-15.

19. Parke WW, Settles HE, Bunger PC, Vandenmark RE. Malformations of the liver: Some prenatal and postnatal developmental aspects. Clin Anat 1996; 9: 309-16.

20. Auh YH, Rosen A, Rubenstein WA, Engel IA, Whalen JP, Kazam E. CT of the papillary process of the caudate lobe of the liver. Am I Roentgenol 1984; 142: 535-8.

21. Joshi SD, Joshi SS, Athavale SA. Some interesting observations on the surface features of the liver and their clinical implications. Singapore Med J 2009; 50: 715-19.

22. Sarala HS, Jyothilakshmi TK, Shubha R Morphological variations of caudate lobe of the liver and their clinical implications. Int'l J Anat Res 2015; 3: 980-83.

23. Dodds WJ, Erickson SJ, Taylor AJ, Lawson TL, Stewart ET. Caudate lobe of the liver: Embryology, and pathology. Am J Roentgenol 1990; 154: 87-93.

24. Datta AK. Essentials of human anatomy Part I. $9^{\text {th }}$ edition. Kolkata: Current Books International; 2010: 237-52.

25. Pamidi N, Nayak S and Vollala VR. Cystogastrocolic fold and associated atrophy of the gallbladder. Singapore Med J 2008; 49: 250-1.

26. Nayak SB. Abnormal peritoneal fold connecting the greater omentum with the liver, gallbladder, right kidney and lesser omentum. Bratisl Lek Listy 2009; 110: 736-7.

27. Baruah P, Choudhury PR. Anomalies of liver morphology: A study on cadaveric liver. Int'l J Anat Res 2016; 4: 3284-88.

28. Custer JR, Shafer RB. Changes in liver scan following splenectomy. J Nucl Med 1975; 16: 194-5.

29. Sangeeta M, Varalakshmi KL, Naik S. Study of the morphometry of the liver. Indian J Appl Res 2014; 4: 441-3.

30. Arya RS, Arya RC, Kumar A, Basan K, Singh B, Jangde S. Study of cadaveric Liver lobe anomaly. Int'l J Clin Anat Physio 2015; 2: 212-5. 